\title{
LiSbS $_{2}-m C 16:$ Structure Determination from X-ray Powder Diffraction Data
}

\author{
Sebastian Huber ${ }^{[a]}$ and Arno Pfitzner*[a] \\ Dedicated to Professor Heinz Dieter Lutz on the Occasion of His 80th Birthday
}

Keywords: Antimony; Lithium; Sulfur; Powder diffraction; Rietveld method

\begin{abstract}
Monoclinic $\mathrm{LiSbS}_{2}-m C 16$ was synthesized by solid-state reaction of $\mathrm{Li}_{2} \mathrm{~S}, \mathrm{Sb}$, and $\mathrm{S}$ in the ratio $1: 2: 5$ at a temperature of $900{ }^{\circ} \mathrm{C}$. The excess of sulfur serves as a kind of flux and is not incorporated in the structure. The product is air and moisture sensitive. The crystal structure of the dark red product was determined from X-ray powder diffraction data at $293 \mathrm{~K}$. LiSbS $-m C 16$ crystallizes in the space group $C 2 / c$ (no. 15) with $a=8.0205(8) \AA, b=7.9243(8) \AA, c=6.6987(7) \AA$, $\beta=126.303(6)^{\circ}, V=343.11(7) \AA^{3}$, and $Z=4$. It forms an ordered
\end{abstract}

$\mathrm{NaCl}$ type superstructure, which shows two different sites for the cations, whereas the cubic high temperature modification $c F 8$ exhibits only one position with a mixed occupation by lithium and antimony. Lithium has a slightly distorted octahedral coordination by sulfur. The distortion of the octahedral coordination polyhedron is much stronger in the case of antimony. Therefore it is better described as a $2+2+2$ coordination mode.

\section{Introduction}

The phase diagram of $\mathrm{Li}_{2} \mathrm{~S}$ and $\mathrm{Sb}_{2} \mathrm{~S}_{3}$ was first described 1983 by Olivier-Fourcade et al. ${ }^{[1,2]}$ Two interesting compounds in this system are $M_{3}^{\mathrm{I}} P n Q_{3}\left(\mathrm{Li}_{3} \mathrm{SbS}_{3}\right)$ and $M^{\mathrm{I}} P n Q_{2}$ $\left(\mathrm{LiSbS}_{2}\right)$ since especially for the Li rich composition an enhanced ion conductivity is observed. ${ }^{[3]} M^{\mathrm{I}}$ (alkali metal, copper, or silver) as well as $P n$ (pnicogen) and $Q$ (chalcogen) can be substituted for both formula types. So a whole variety of compounds results with similar structural motifs in all substituted compounds. The $M_{3}^{\mathrm{I}} P n Q_{3}$ compounds show interesting physical properties. $\mathrm{Li}_{3} \mathrm{SbS}_{3},{ }^{[3]} \mathrm{Na}_{3} \mathrm{SbS}_{3},{ }^{[4,5]}$ and $\mathrm{Na}_{3} \mathrm{SbSe}_{3}{ }^{[6]}$ are good ion conductors with a specific conductivity of $\sigma=$ $5.4 \times 10^{-5} \Omega^{-1} \cdot \mathrm{cm}^{-1}$ at $573 \mathrm{~K}\left(\mathrm{Li}_{3} \mathrm{SbS}_{3}\right)$. The copper compounds $\mathrm{Cu}_{3} \mathrm{SbS}_{3}{ }^{[7-10]}$ and $\mathrm{Cu}_{3} \mathrm{SbSe}_{3}{ }^{[11]}$ are interesting thermoelectric materials, ${ }^{[12,13]}$ and $\mathrm{Ag}_{3} \mathrm{SbS}_{3}{ }^{[14]}$ is a piezo-electric ion conductor with a specific conductivity of $\sigma=5 \times 10^{-2} \Omega^{-1} \cdot \mathrm{cm}^{-1}$ at $473 \mathrm{~K} \cdot{ }^{[15,16]}$ Most of the heavier homologous compounds are also structurally characterized, i.e., $\mathrm{K}_{3} \mathrm{SbS}_{3},{ }^{[5]} \mathrm{K}_{3} \mathrm{SbSe}_{3},{ }^{[17]}$ $\mathrm{Rb}_{3} \mathrm{SbSe}_{3},{ }^{[17]} \mathrm{Cs}_{3} \mathrm{SbSe}_{3},{ }^{[17]} \mathrm{Li}_{3} \mathrm{AsS}_{3},{ }^{[3,18]} \quad \mathrm{Na}_{3} \mathrm{AsS}_{3},{ }^{[5,19]}$ $\mathrm{Na}_{3} \mathrm{AsSe}_{3},{ }^{[20]} \quad \mathrm{K}_{3} \mathrm{AsS}_{3},{ }^{[5]} \quad \mathrm{K}_{3} \mathrm{AsSe}_{3},{ }^{[20]} \quad \mathrm{K}_{3} \mathrm{BiSe}_{3},{ }^{[21,22]}$ $\mathrm{Rb}_{3} \mathrm{BiSe}_{3},{ }^{[21,22]} \quad \mathrm{Cs}_{3} \mathrm{BiSe}_{3},{ }^{[21,22]} \quad \mathrm{Ag}_{3} \mathrm{AsS}_{3},{ }^{[23,24]}$ and $\mathrm{Ag}_{3} \mathrm{AsSe}_{3} \cdot{ }^{[25-27]} \mathrm{M}^{\mathrm{I}} \mathrm{Pn} Q_{2}$ with $\mathrm{Pn}=\mathrm{Sb}$ and $Q=\mathrm{S}$ show interesting crystal chemical features. Both $\mathrm{AgSbS}_{2}$ and $\mathrm{NaSbS}_{2}$ crystallize in two different modifications, a cubic one $(c F 8)$

* Prof. Dr. A. Pfitzner

Fax: +49-941-943-814551

E-Mail: arno.pfitzner@chemie.uni-regensburg.de

[a] Institut für Anorganische Chemie

Universität Regensburg

Universitätsstraße 31

93040 Regensburg, Germany

$\square$ Supporting information for this article is available on the WWW under http://dx.doi.org/10.1002/zaac.201400058 or from the author. with rock salt structure type and disorder of $M^{\mathrm{I}}$ and Sb (space group $F m \overline{3} m$ ) at high temperature, ${ }^{[28,29]}$ and a monoclinic one $\left[m C 16\left(M^{\mathrm{I}}=\mathrm{Na}\right), m C 32\left(M^{\mathrm{I}}=\mathrm{Ag}\right)\right]$ with an ordered distribution of the cations (space group $C 2 / c$ ) at ambient temperature. ${ }^{[29,30]}$ To date $\mathrm{KSbS}_{2}$ is known only in the monoclinic form with space group $C 2 / c .{ }^{[31]}$ Further $M^{\mathrm{I}} P n Q_{2}$ type compounds, which crystallize in the rock salt structure type and disorder of $M^{\mathrm{I}}$ and $P n$ are $\mathrm{LiSbSe}_{2},{ }^{[32]} \mathrm{NaSbSe}_{2},{ }^{[33]}$ $\mathrm{LiAsSe}_{2},{ }^{[34]} \mathrm{NaAsSe}_{2},{ }^{[33]} \mathrm{LiBiS}_{2},{ }^{[35]} \mathrm{NaBiS}_{2},{ }^{[35]} \mathrm{KBiS}_{2},{ }^{[35]}$ $\mathrm{NaBiSe}_{2},{ }^{[36]}$ and $\mathrm{KBiSe}_{2} \cdot{ }^{[36]}$ In contrast, three different modifications $\left(\alpha-, \beta-, \gamma-\mathrm{LiSbS}_{2}\right)$ are reported in the case of $\mathrm{LiSbS}_{2} \cdot{ }^{[1,2]} \beta-\mathrm{LiSbS}_{2}$ was reported to crystallize in an ordered $\mathrm{NaCl}$ type superstructure in the rhombohedral space group $R \overline{3}$, whereas $\gamma-\mathrm{LiSbS}_{2}$ is isotypic with $\mathrm{NaSbS}_{2}-c F 8$ (rock salt structure type). For $\alpha-\mathrm{LiSbS}_{2}$ only a monoclinic cell without any structure details was reported. ${ }^{[1]}$ All $M^{\mathrm{I}} \mathrm{SbS}_{2}$ compounds listed above crystallize either in space group $F m \overline{3} m$ with a perfect rock salt structure type $\left(M^{\mathrm{I}} P n Q_{2}-c F 8\right)$ and only one cation position with mixed occupation by $M^{\mathrm{I}}$ and $\mathrm{Sb}$, or in a fully ordered rock salt superstructure type $\left(M^{\mathrm{I}} P n Q_{2}-m C 16\right.$ or -32) with two or even three $\left(M^{\mathrm{I}}=\mathrm{Ag}\right)$ different cation sites and no mixed occupation. We will consequently use the Pearson symbols instead of Greek letters in order to avoid any confusion.

Herein we report on the synthesis and on the structure determination of $\mathrm{LiSbS}_{2}-m C 16$ from X-ray powder diffraction data.

\section{Results and Discussion}

\section{Structure Determination}

The crystal structure of $\mathrm{LiSbS}_{2}-m C 16$ was determined from $\mathrm{X}$-ray diffraction data of a microcrystalline powder. Crystallo- 
graphic data are summarized in Table 1. Atomic coordinates and isotropic displacement parameters are collected in Table 2. Table 3 lists the anisotropic displacement parameters of antimony and sulfur, and Table 4 shows selected interatomic distances.

\section{Structure Determination from X-ray Powder Diffraction Data}

The crystal structure of $\mathrm{LiSbS}_{2}-m C 16$ was determined from X-ray powder diffraction with JANA2006. ${ }^{[37]}$ The profile refinement was done by the le Bail algorithm. Background was

Table 1. Crystallographic data for the structure analysis of $\mathrm{LiSbS}_{2}-m C 16$

\begin{tabular}{|c|c|}
\hline & $\mathrm{LiSbS}_{2}$ \\
\hline Formula weight $/ \mathrm{g} \cdot \mathrm{mol}^{-1}$ & 192.8 \\
\hline Color & dark red \\
\hline Crystal system & monoclinic \\
\hline Space group & $C 2 / c$ (No. 15) \\
\hline \multicolumn{2}{|l|}{ Lattice constants from X-ray powder data } \\
\hline$a / \AA$ & $8.0205(8)$ \\
\hline$b / \AA ̊$ & 7.9243(8) \\
\hline$c / \AA ̊$ & $6.6987(7)$ \\
\hline$\beta \mu^{\circ}$ & $126.303(6)^{\circ}$ \\
\hline Cell volume $/ \AA^{3}, Z$ & $343.11(7), 4$ \\
\hline Density $\rho_{\text {calc }} / \mathrm{g} \cdot \mathrm{cm}^{-3}$ & 3.7313 \\
\hline \multirow{2}{*}{ Diffractometer } & STOE STADI P \\
\hline & $\begin{array}{l}\text { Mythen } 1 \mathrm{~K}, \mathrm{Mo}-K_{\alpha 1} \\
\lambda=0.70926 \AA\end{array}$ \\
\hline Absorption coefficient $\mu\left(\mathrm{Mo}-K_{\alpha 1}\right) / \mathrm{mm}^{-1}$ & 8.937 \\
\hline Temperature $/{ }^{\circ} \mathrm{C}$ & 20 \\
\hline $2 \theta$ range $/^{\circ}$ & $2.000 \leq 2 \theta \leq 73.985$ \\
\hline Step width $2 \theta 1^{\circ}$ & 0.015 \\
\hline No. of measured points & 4800 \\
\hline No. of parameters, constraints & 33,1 \\
\hline Program & JANA2006 ${ }^{[37]}$ \\
\hline Profile function & Pseudo-Voigt \\
\hline Background function & $\begin{array}{l}\text { Legendre polynomial } 3 . \\
\text { order }\end{array}$ \\
\hline Final $R p, w R p$, expected $w R p$ & $0.0540,0.0721,0.0346$ \\
\hline Final $R / w R$ (obs. reflections) & $0.0369,0.0345$ \\
\hline Final $R / w R$ (all reflections) & $0.0488,0.0389$ \\
\hline GooF & 2.09 \\
\hline $\begin{array}{l}\text { Largest difference peak } \Delta \rho_{\max } \text { and hole } \\
\Delta \rho_{\min } / \mathrm{e} \cdot \AA^{-3}\end{array}$ & $0.55,-0.70$ \\
\hline
\end{tabular}

Table 2. Atomic coordinates and equivalent isotropic displacement parameters $U_{\text {eq }} / \AA^{2}$ for $\mathrm{LiSbS}_{2}-m C 16$.

\begin{tabular}{llllll}
\hline Atom & Wyckoff & $x$ & $y$ & $z$ & $U_{\text {eq }}{ }^{\text {a) }}$ \\
\hline $\mathrm{Sb}$ & $4 e$ & 0 & $0.358(1)$ & $1 / 4$ & $0.015(3)$ \\
$\mathrm{S}$ & $8 f$ & $0.777(2)$ & $0.154(3)$ & $0.262(2)$ & $0.017(9)$ \\
$\mathrm{Li}$ & $4 e$ & 0 & $0.12(3)$ & $3 / 4$ & $0.03{ }^{\mathrm{b})}$ \\
\hline
\end{tabular}

a) $U_{\text {eq }}$ is defined as one third of the trace of the orthogonalized $U_{i j}$ tensor. b) $U_{i s o}(\mathrm{Li})$ is fixed during refinement.
Table 4. Selected interatomic distances / $\AA$ for $\mathrm{LiSbS}_{2}-m C 16$.

\begin{tabular}{lll}
\hline $\mathrm{Sb}-\mathrm{S}$ & $2 \times$ & $2.45(2)$ \\
& $2 \times$ & $2.77(1)$ \\
$\mathrm{Li}-\mathrm{S}$ & $2 \times$ & $3.20(2)$ \\
& $2 \times$ & $2.65(2)$ \\
& $2 \times$ & $2.8(2)$ \\
& $2 \times$ & $2.9(2)$ \\
\hline
\end{tabular}

corrected by a Legendre polynomial of third order. Peak profiles were fitted by a Pseudo-Voigt profile function within a range of $8 *$ FWHM. Refined parameters were $G V, G W$ and $L Y$. Divergence was taken into account for fitting the peak asymmetry. Refined parameters were $H / L$ and $S / L$, both constrained $H / L=S / L$. The unit cell parameters $a, b, c, \beta$ and the zero point were also refined. Minor reflections caused by impurities of elemental sulfur were excluded from the refinement. The observed and fitted diffraction patterns are shown in Figure 1. Space group $C 2 / c$ was determined with JANA2006 and the crystal structure was solved with Superflip implemented therein. ${ }^{[37,38]}$ The positions of all atoms were located by this procedure. The Rietveld algorithm implemented in the JANA2006 program package was used for the structure refinement. The positions of all atoms were refined and anisotropic displacement parameters were used for the heavier atoms.

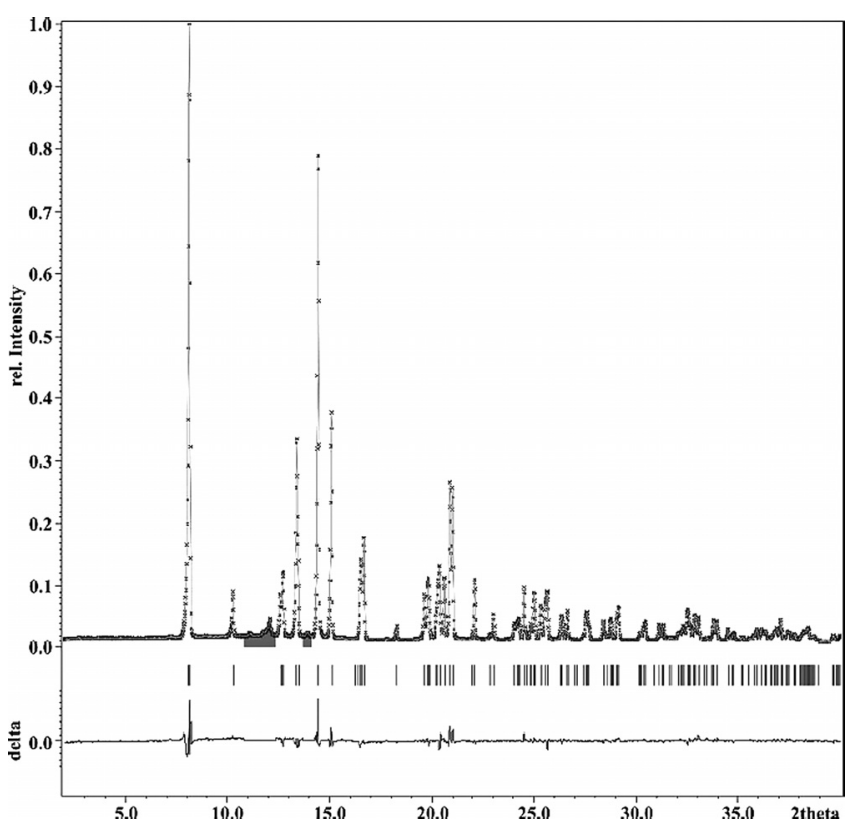

Figure 1. Section of the fitted powder profile from $2.0<2 \theta<40.0^{\circ}$. We should remind that the wavelength is only $\lambda=0.70926 \AA$ (Mo$\left.K_{\alpha 1}\right)$ instead of $\lambda=1.540598 \AA\left(\mathrm{Cu}-K_{\alpha 1}\right)$, which is typically used. Observed $(\times)$, fitted (gray line), and difference profiles of $\mathrm{LiSbS}_{2}$. Minor impurities due to elemental sulfur are omitted from the refinement (gray bar). The whole diagram is displayed in Figure S1.

Table 3. Anisotropic displacement parameters $U_{i j} / \AA^{2}$ for $\mathrm{LiSbS}_{2}-m C 16$.

\begin{tabular}{lllllll}
\hline Atom & $U_{11}$ & $U_{22}$ & $U_{33}$ & $U_{23}$ & $U_{13}$ & $U_{12}$ \\
\hline $\mathrm{Sb}$ & $0.013(3)$ & $0.012(4)$ & $0.017(3)$ & 0 & $0.009(3)$ & 0 \\
$\mathrm{~S}$ & $0.019(9)$ & $0.02(1)$ & $0.016(8)$ & $-0.01(1)$ & $0.010(8)$ & $-0.004(9)$ \\
\hline
\end{tabular}


However, the displacement parameter for lithium was fixed to a reasonable value of $U_{\text {iso }}=0.03 \AA^{2}$ in the final stages of the refinement. No significant residual electron density was detected in the final difference Fourier map. At this stage of the refinement the significance of the position for $\mathrm{Li}$ was checked. The $R$ values increased when $\mathrm{Li}$ was excluded from the refinement and Difference Fourier syntheses had a maximum exactly at the $\mathrm{Li}$ position. This means that even $\mathrm{Li}$ can be refined from these data.

The X-ray diffraction pattern was refined to final $R$-values of $R p=5.40 \%$ and $w R p=7.21 \%$ (expected $3.46 \%$ ), based on 4800 measured points. The structure refinement converged to final $R$-values of $R_{o b s}\left(R_{\text {all }}\right)=3.69 \%(4.88 \%)$ and $w R_{o b s}$ $\left(w R_{\text {all }}\right)=3.45 \%(3.89 \%)$.

\section{Structure Description and Discussion}

$\mathrm{LiSbS}_{2}-m C 16$ crystallizes in the space group $C 2 / c$. The atoms are arranged in an ordered $\mathrm{NaCl}$ superstructure type. The formation of the superstructure results from the separation of $\mathrm{Li}^{+}$and $\mathrm{Sb}^{3+}$ on two different sites (see Table 2 and Figure 2). Both sites are fully occupied with either antimony or lithium. Lithium has a slightly distorted octahedral coordination by sulfur. The distances $d(\mathrm{Li}-\mathrm{S})$ are in the range from $2.66 \AA$ to $2.9 \AA$ (see Figure 3). The distortion of the octahedral coordination sphere is much more pronounced in the case of antimony. It has a coordination of $2+2+2$ sulfur atoms. ${ }^{[39]}$ The distances $d(\mathrm{Sb}-\mathrm{S}$ ) are $2.45 \AA, 2.77 \AA$, and $3.20 \AA$ (see Figure 3).

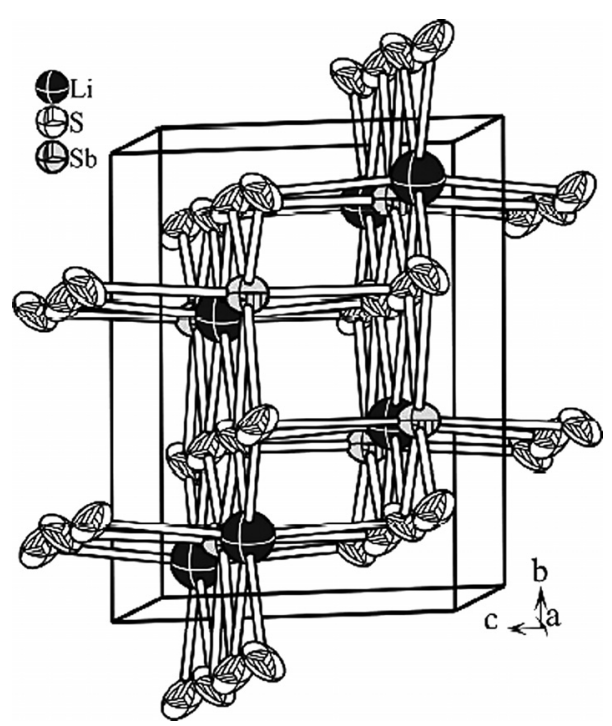

Figure 2. Section of the crystal structure of $\mathrm{LiSbS}_{2}-m C 16$.

Olivier-Fourcade et al. described the phase diagram of $\mathrm{Li}_{2} \mathrm{~S}$ and $\mathrm{Sb}_{2} \mathrm{~S}_{3}$ in $1983 .^{[1,2]}$ They reported that $\mathrm{LiSbS}_{2}$ crystallizes in three different modifications $\left(\alpha-, \beta-, \gamma-\operatorname{LiSbS}_{2}\right) . \alpha-\mathrm{LiSbS}_{2}$ was described as monoclinic without any structure details. $\beta$ $\mathrm{LiSbS}_{2}\left(\mathrm{LiSbS}_{2}-h R 72\right)$ crystallizes in an ordered $\mathrm{NaCl}$ superstructure, and $\gamma-\mathrm{LiSbS}_{2}\left(\mathrm{LiSbS}_{2}-c F 8\right)$ forms a cubic structure of the $\mathrm{NaCl}$ type. Only a powder pattern was published for the $\alpha$-phase without any structure details. The simulated powder

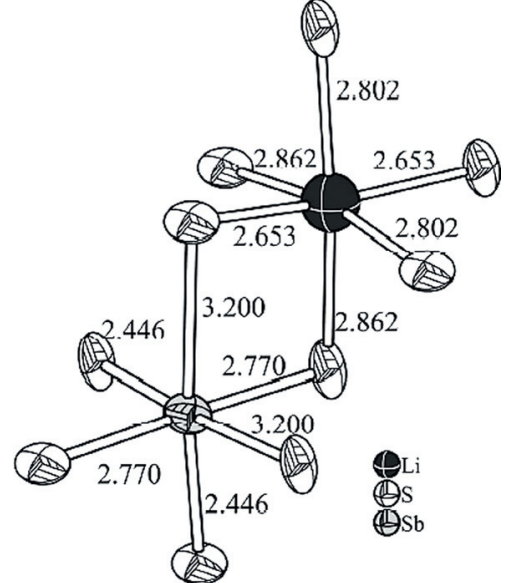

Figure 3. Octahedral coordination spheres of antimony and lithium by sulfur.

pattern of the title compound does not match the reflection positions of $\alpha-\mathrm{LiSbS}_{2}$ described in literature. Two explanations are possible for this observation: (1) the title compound is a fourth modification of $\mathrm{LiSbS}_{2}$, or (2) the published powder pattern for $\alpha-\mathrm{LiSbS}_{2}$ results from more than one phase and the title compound is the hitherto unknown $\alpha$-phase of $\mathrm{LiSbS}_{2}$.

From a crystal chemical viewpoint $\mathrm{LiSbS}_{2}-m C 16$ fits quite well to literature data on the heavier homologous compounds. Both $\mathrm{NaSbS}_{2}-m C 16$ and $\mathrm{KSbS}_{2}-m C 16$ crystallize in the space group $C 2 / c$. The ratios of the cell parameter are in the same range and show some systematic trends (see Table 5). ${ }^{[29,31]}$ The alkali metal cations therein have a slightly distorted octahedral coordination by sulfur. The distances $d\left(M^{\mathrm{I}}-\mathrm{S}\right)$ increase from lithium to potassium, and they are in the usual range (see Table 6). In contrast, the antimony sulfur bonds show an interesting change. For $\mathrm{LiSbS}_{2}-m C 16$ antimony has a $2+2+$ 2 coordination by sulfur with four regular distances $d(\mathrm{Sb}-\mathrm{S})=$

Table 5. Comparison of the unit cell parameters of $M^{\mathrm{I} S b S} \mathrm{Sb}_{2}-m C 16$ $\left(M^{\mathrm{I}}=\mathrm{Li}, \mathrm{Na}, \mathrm{K}\right)$.

\begin{tabular}{llll}
\hline & $\mathrm{LiSbS}_{2}$ & $\mathrm{NaSbS}_{2}{ }^{[29]}$ & $\mathrm{KSbS}_{2}{ }^{[31]}$ \\
\hline Space group & & \multicolumn{1}{c}{$C 2 / c$} & \\
$a / \AA$ & $8.0205(8)$ & $8.232(1)$ & $8.75(1)$ \\
$b / \AA$ & $7.9243(8)$ & $8.252(2)$ & $8.98(1)$ \\
$c / \AA$ & $6.6987(7)$ & $6.836(1)$ & $6.84(1)$ \\
$\beta /{ }^{\circ}$ & $126.303(6)$ & $124.28(1)$ & $121.6(1)$ \\
$V / \AA^{3}$ & $343.11(7)$ & 383.71 & 457.76 \\
$a / b$ & 1.012 & 0.998 & 0.974 \\
$a / c$ & 1.197 & 1.204 & 1.279 \\
$b / c$ & 1.183 & 1.207 & 1.313 \\
\hline
\end{tabular}

Table 6. Comparison of $d(\mathrm{Sb}-\mathrm{S})$ and $d\left(M^{\mathrm{I}}-\mathrm{S}\right)$ in $M^{\mathrm{I}} \mathrm{SbS}_{2}-m C 16\left(M^{\mathrm{I}}=\right.$ $\mathrm{Li}, \mathrm{Na}, \mathrm{K})$.

\begin{tabular}{lllll}
\hline & & $\mathrm{LiSbS}_{2}$ & $\mathrm{NaSbS}_{2}{ }^{[29]}$ & $\mathrm{KSbS}_{2}{ }^{[31]}$ \\
\hline$d(\mathrm{Sb}-\mathrm{S}) / \AA$ & $2 \times$ & 2.45 & 2.43 & 2.41 \\
& $2 \times$ & 2.77 & 2.77 & 2.76 \\
& $2 \times$ & 3.20 & 3.41 & 3.89 \\
$d\left(M^{\mathrm{I}}-\mathrm{S}\right) / \AA$ & $2 \times$ & 2.65 & 2.91 & 3.17 \\
& $2 \times$ & 2.8 & 2.92 & 3.17 \\
& $2 \times$ & 2.9 & 2.95 & 3.20 \\
\hline
\end{tabular}


2.45 and $2.77 \AA$ and two longer distances $d(\mathrm{Sb}-\mathrm{S})=3.20 \AA$, so called secondary bonds. The four regular distances between antimony and sulfur are more or less identical in all three compounds. However, the length of the secondary bonds increases significantly, i.e., the secondary bond length is $d(\mathrm{Sb}-\mathrm{S})=$ $3.20 \AA$ for $\mathrm{LiSbS}_{2}-m C 16$ and $d(\mathrm{Sb}-\mathrm{S})=3.89 \AA$ in $\mathrm{KSbS}_{2}-m C 16$ (see Table 6). An increasing ionicity from the lithium to the potassium compound might serve as an explanation for this finding. This trend also might be the reason why $M^{\mathrm{I} S b} Q_{2}\left(M^{\mathrm{I}}=\mathrm{Li}, \mathrm{Na}, Q=\mathrm{S}, \mathrm{Se}\right)^{[1,2,29,32,33]}$ form a cubic rock salt structure $(c F 8)$ with disorder of $M^{\mathrm{I}}$ and $\mathrm{Sb}$ at elevated temperatures.

\section{Conclusions}

$\mathrm{LiSbS}_{2}-m C 16$ was obtained by reaction of $\mathrm{Li}_{2} \mathrm{~S}, \mathrm{Sb}$, and $\mathrm{S}$. It represents the hitherto unknown so-called $\alpha$-phase of $\mathrm{LiSbS}_{2}$. It crystallizes isotypic with the heavier homologous compounds in the space group $C 2 / c$ in an ordered $\mathrm{NaCl}$ superstructure type. The diffraction pattern was fitted to final $R$ values of $R p=5.40 \%$ and $w R p=7.21 \%$. The structure refinement converged at final $R$-values of $R_{o b s}=3.69 \%$ and $w R_{o b s}$ $=3.45$. A systematic increase of the secondary bond lengths is observed from $\mathrm{LiSbS}_{2}-m C 16$ to $\mathrm{KSbS}_{2}-m C 16$. In contrast, the regular bond lengths do not change in this series.

\section{Experimental Section}

$\mathrm{LiSbS}_{2}-m C 16$ was obtained by the reaction of $\mathrm{Li}_{2} \mathrm{~S}(99.9 \%$, Alfa Aesar), Sb (99.999\%, Chempur), and S (99.9995\%, Merck) in the ratio 1:2:5. The excess of sulfur serves as flux to obtain a crystalline product. All manipulations were performed in a glove box in an argon atmosphere. The starting materials were filled into graphite crucibles and fused in evacuated silica ampoules. The reagents were annealed for 3 weeks at $900{ }^{\circ} \mathrm{C}$ and cooled down to room temperature over $15 \mathrm{~h}$. The product is air and moisture sensitive. The dark red sample was ground and filled in glass capillaries $(\varnothing=0.3 \mathrm{~mm})$. X-ray diffraction measurements were carried out with a STOE STADI P diffractometer with monochromatic Mo- $K_{\alpha 1}$-radiation $(\lambda=0.70926 \AA)$, a Ge-monochromator, and a Mythen $1 \mathrm{~K}$ detector at $293 \mathrm{~K}$. The $2 \theta$ range was $2.000^{\circ}$ to $73.985^{\circ}$ with a step-width of $0.015^{\circ}$. Four powder patterns were summed up for a better statistics and were subsequently used for the structure determination. The data were processed using JANA2006. ${ }^{[37]}$ Background was corrected using a Legendre polynomial of third order and the profile was fitted by a Pseudo-Voigt profile function. The crystal structure was solved by Superflip. ${ }^{[38]}$ The structure was refined with the Rietveld algorithm implemented in JANA2006. Antimony and sulfur were refined by using anisotropic displacement parameters. The isotropic displacement parameter of lithium was fixed at $U_{\text {iso }}=0.03 \AA^{2}$ in the final stages of the refinement.

Further details of the crystal structure investigations may be obtained from the Fachinformationszentrum Karlsruhe, 76344 EggensteinLeopoldshafen, Germany (Fax: +49-7247-808-666; E-Mail: crysdata@fiz-karlsruhe.de, http://www.fiz-karlsruhe.de/request for deposited data.html) on quoting the depository number CSD-427506.

Supporting Information (see footnote on the first page of this article): Figure S1: Whole range powder diffraction pattern for $\mathrm{LiSbS}_{2}-m C 16$ measured with molybdenum radiation $(\lambda=0.70926 \AA)$.

\section{References}

[1] J. Olivier-Fourcade, L. Izghouti, M. Maurin, E. Philippot, Rev. Chim. Miner. 1983, 20, 186.

[2] J. Olivier-Fourcade, M. Maurin, E. Philippot, Rev. Chim. Miner. 1983, 20, 196.

[3] S. Huber, C. Preitschaft, R. Weihrich, A. Pfitzner, Z. Anorg. Allg. Chem. 2012, 638, 2542.

[4] C. Pompe, A. Pfitzner, Z. Anorg. Allg. Chem. 2013, 639, 296.

[5] H. Sommer, R. Hoppe, Z. Anorg. Allg. Chem. 1977, 480, 199.

[6] C. Pompe, A. Pfitzner, Z. Anorg. Allg. Chem. 2012, 638, 2158.

[7] A. Pfitzner, Z. Anorg. Allg. Chem. 1994, 620, 1992.

[8] A. Pfitzner, Z. Kristallogr. 1998, 213, 228.

[9] S. Karup-Møller, E. Makovicky, Am. Mineral. 1974, 59, 889.

[10] B. J. Skinner, F. D. Luce, E. Makovicky, Econ. Geol. 1972, 67, 924.

[11] A. Pfitzner, Z. Anorg. Allg. Chem. 1995, 621, 685.

[12] E. J. Skoug, J. D. Cain, D. T. Morelli, Appl. Phys. Lett. 2010, 96, 181905.

[13] M. Kirkham, P. Majsztrik, E. Skoug, D. Morelli, H. Wang, W. D. Porter, E. A. Payzant, E. Lara-Curzio, J. Mater. Res. 2011, 26, 2001.

[14] D. Harker, J. Chem. Phys. 1936, 4, 381.

[15] K. A. Schönau, S. A. T. Redfern, J. Appl. Phys. 2002, 92, 7415.

[16] M. Leitl, Dissertation, Regensburg, 2007.

[17] W. Bronger, A. Donike, D. Schmitz, Z. Anorg. Allg. Chem. 1999, 625,435

[18] D.-Y. Seung, P. Gravereau, L. Trut, A. Levasseur, Acta Crystallogr., Sect. C 1998, 54, 900.

[19] M. Palazzi, Acta Crystallogr., Sect. B 1976, 32, 3175.

[20] W. Bronger, A. Donike, D. Schmitz, Z. Anorg. Allg. Chem. 1998, $624,553$.

[21] W. Bronger, A. Donike, D. Schmitz, Z. Anorg. Allg. Chem. 1996, 622,1003

[22] W. Bronger, A. Donike, D. Schmitz, Z. Anorg. Allg. Chem. 1997, 623,1715

[23] D. Harker, J. Chem. Phys. 1936, 4, 381.

[24] P. Engel, W. Nowacki, Acta Crystallogr., Sect. B 1968, 24, 77.

[25] K. Sakai, T. Koide, T. Matsumoto, Acta Crystallogr., Sect. B 1978, $34,3326$.

[26] K. Kihara, T. Matsumoto, Z. Kristallogr. 1986, 177, 211.

[27] M. G. Kanatzidis, J.-H. Chou, J. Solid State Chem. 1996, 127, 186.

[28] S. N. Hoda, L. L. Y. Chang, Am. Mineral. 1975, 60, 621.

[29] J. Olivier-Fourcade, E. Philippot, M. Maurin, Z. Anorg. Allg. Chem. 1978, 446, 159.

[30] H. Effenberger, W. H. Paar, D. Topa, A. J. Criddle, M. Fleck, Am. Mineral. 2002, 87, 753.

[31] H. A. Graf, H. Schaefer, Z. Anorg. Allg. Chem. 1975, 414, 211.

[32] V. A. Bazakutsa, N. I. Gnidash, V. B. Lazarev, E. I. Rogacheva, A. V. Salov, L. N. Sukhorukova, M. P. Vasil'eva, S. I. Berul, Russ. J. Inorg. Chem. 1973, 18, 1722.

[33] B. Eisenmann, H. Schaefer, Z. Anorg. Allg. Chem. 1979, 456, 87.

[34] T. K. Bera, J.-I. Jang, S. Jungh Wan, C. D. Malliakas, A. J. Freeman, J. B. Ketterson, M. G. Kanatzidis, J. Am. Chem. Soc. 2010, 132,3484 .

[35] O. Glemser, M. Filcek, Z. Anorg. Allg. Chem. 1955, 279, 321.

[36] G. Gattow, J. Zemann, Z. Anorg. Allg. Chem. 1955, 279, 324.

[37] V. Petricek, M. Dusek, L. Palatinus, The Crystallographic Computing System JANA2006. Institute of Physics, Praha, Czech Republic, 2006.

[38] L. Palatinus, G. J. Chapuis, J. Appl. Crystallogr. 2007, 40, 786.

[39] A. Pfitzner, D. Kurowski, Z. Kristallogr. 2000, 215, 373.

Received: February 7, 2014

Published Online: April 7, 2014 